\section{The Index of Preprogramming (IP): A statistical method for evaluating the role of feedback in simple movements}

\author{
RICHARD A. SCHMIDT \\ Department of Physical Education \\ The University of Michigan, Ann Arbor, Mich. 48104
}

A preprogrammed response is one in which the motor commands are determined in advance and which is carried out without feedback control. The Index of Preprogramming (IP) is proposed as a measure of preprogramming or of the degree of feedback involvement in movement. Evidence presented indicates that the IP is sensitive to variables which should manipulate the degree of preprogramming. Possible limitations of the IP as well as potential applications to research on motor skills are discussed.
In a very trivial sense, all movements are preprogrammed; that is, S always has some "plan" or "intention" concerning the responses he has been asked to execute. But this view of preprogramming, being so general that it describes all movements, is not particularly useful. According to the most common use of the term, preprogrammed responses are those in which all of the decisions concerning the neurological commands to the muscles, including instructions about the timing of contractions and their forces, are determined in advance. It follows, then, that feedback from the particular preprogrammed movement does not play a role in the control of that movement, and the movement is carried out as programmed without regard to its correctness. The analogy to the computer is clear. The instructions are the written commands in the form of a computer program, and when the program is executed, the commands are followed faithfully even if, as is so often the case, there is an error in the program and the results are incorrect.

The preprogramming hypothesis has been one of the most important explanatory theories for the control of ballistic movement of short duration, with considerable recent interest in preprogramming (e.g., Adams, 1971; Henry, 1960; Hick, 1948; Schmidt, $1969,1971)$. However, although it is a simple matter to define a preprogrammed response as one which is completely devoid of feedback control, the evidence that such responses exist is difficult to muster (1) the movement can be executed with all feedback channels eliminated or that (2) feedback is present in the movement but is not used. Strictly speaking, neither of these two possibilities has been shown experimentally. There are a number of because it must be shown either that indirect lines of evidence for preprogramming, however, and the most convincing uses the fact that the processing of information is relatively slow, requiring on the order of 100-200 msec (Keele \& Posner, 1968). If this is true, then Hick's (1948) finding that $S$ could initiate a rapid corrective movement and bring it to a stop $100 \mathrm{msec}$ later is indirect evidence that the instructions to stop the movement had to be issued prior to its initiation; for if the "stop" instructions were triggered by the location of the limb during movement, the $100-\mathrm{msec}$ delay in feedback processing time would cause wild overshooting and a very late termination of the movement. Although it is possible that feedback initiates a "reflex" mechanism to stop the movement, this idea has little experimental support and has not really been a popular explanation of Hick's results.

A number of investigators have been interested in determining the laws which describe the conditions under which feedback is used in movements (e.g., Christina, 1970; Henry \& Harrison, 1961; Schmidt, 1969), but efforts have been hampered by a lack of objective methods to assess the role of feedback in movement. If such measures existed, then hypotheses concerning the effects of certain etc.) on the degree of preprogramming could be tested in the laboratory. The present note describes the Index of Preprogramming (IP), which is thought to be sensitive to the degree of feedback involvement in movement. \section{INDEX OF}

\section{PREPROGRAMMING (IP}

The IP is defined for a situation involving what Poulton (1952) described as "receptor anticipation." $\mathrm{S}$ had to use various receptors (e.g., eyes) to track a moving target and execute a movement which was linked temporally to some aspect of the target's movement. The most common example is hitting a pitched ball, where $S$ must swing the bat so that it strikes the ball at the proper location over the plate. In such a situation in the laboratory there is an external target which S watches (e.g., a clock). $S$ starts with his limb in a given position and moves to some other location so that the arrival there is coincident with the clock hand reaching a certain point. A number of scores can then be defined for each of S's attempts. Algebraic error (AE) is the discrepancy (with respect to sign) between S's arrival time at the location and when he should have arrived-negative if early and positive if late. Movement time (MT) is the interval from initiation to termination of the limb movement. Starting time (ST) is the time of movement initiation with reference to the clock variables (such as movement duration,

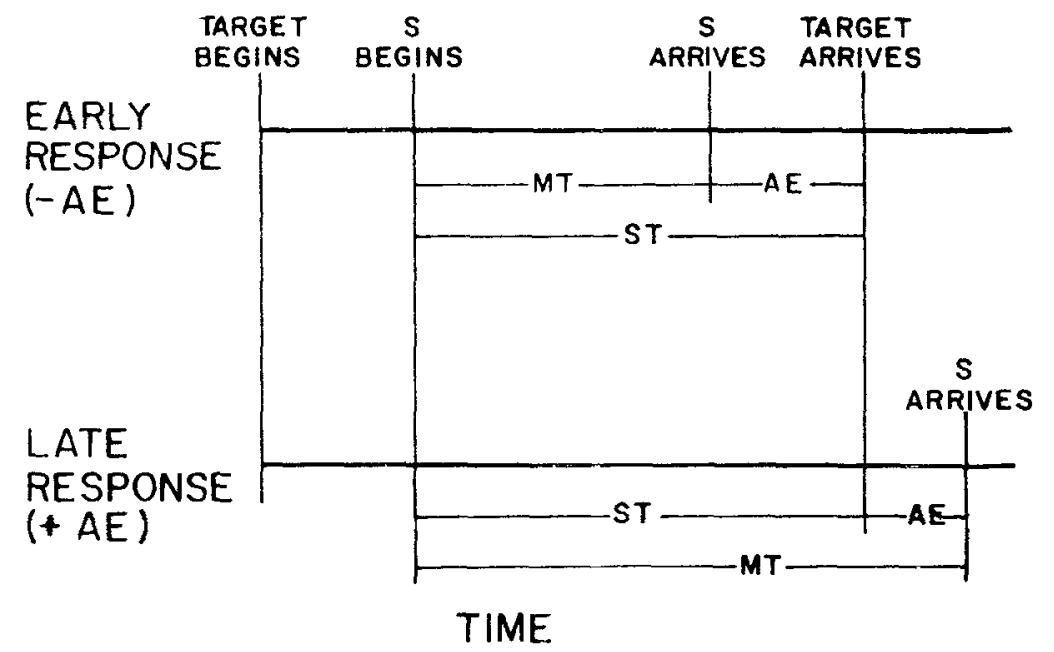

Fig. 1. Schematic diagram showing the measurement of ST, MT, and AE for a response in which $S$ is too early (above) and in which $S$ is too late (below). 
Table 1

Mean IPs (in Parentheses) and $Z^{\prime}$ Transformations as a Function of Various Movement Variables

\begin{tabular}{|c|c|c|c|c|c|}
\hline \multirow[b]{2}{*}{ Distance } & \multicolumn{2}{|c|}{ Slow } & \multicolumn{2}{|c|}{ Fast } & \multirow[b]{2}{*}{ Mean } \\
\hline & Load & No Load & Load & No Load & \\
\hline 15 & $\begin{array}{c}1.11 \\
(.804)\end{array}$ & $\begin{array}{c}0.86 \\
(.696)\end{array}$ & $\begin{array}{c}1.75 \\
(.942)\end{array}$ & $\begin{array}{c}1.70 \\
(.936)\end{array}$ & $\begin{array}{c}1.35 \\
(.874)\end{array}$ \\
\hline 30 & $\begin{array}{c}0.82 \\
(.675)\end{array}$ & $\begin{array}{c}0.74 \\
(.631)\end{array}$ & $\begin{array}{c}1.60 \\
(.922)\end{array}$ & $\begin{array}{c}1.17 \\
(.824)\end{array}$ & $\begin{array}{c}1.08 \\
(.794)\end{array}$ \\
\hline 45 & $\begin{array}{c}0.76 \\
(.641)\end{array}$ & $\begin{array}{c}1.04 \\
(.778)\end{array}$ & $\begin{array}{c}1.66 \\
(.930)\end{array}$ & $\begin{array}{c}1.18 \\
(.806)\end{array}$ & $\begin{array}{c}1.16 \\
(.821)\end{array}$ \\
\hline 60 & $\begin{array}{c}0.75 \\
(.635)\end{array}$ & $\begin{array}{c}0.84 \\
(.686)\end{array}$ & $\begin{array}{c}1.26 \\
(.852)\end{array}$ & $\begin{array}{c}0.89 \\
(.711)\end{array}$ & $\begin{array}{c}0.93 \\
(.730)\end{array}$ \\
\hline \multirow[t]{2}{*}{ Mean } & $\begin{array}{c}0.84 \\
(.686)\end{array}$ & $\begin{array}{c}0.88 \\
(.707)\end{array}$ & $\begin{array}{c}1.57 \\
(.918)\end{array}$ & $\begin{array}{c}1.23 \\
(.809)\end{array}$ & $\begin{array}{c}1.13 \\
(.805)\end{array}$ \\
\hline & \multicolumn{2}{|c|}{$\begin{array}{c}0.86 \\
(.696)\end{array}$} & \multicolumn{2}{|c|}{$\begin{array}{c}1.40 \\
(.886)\end{array}$} & \\
\hline
\end{tabular}

and is measured by the interval from S's first movement until the clock hand arrives at the specified location. Thus, $A E=M T-S T$, so that if $S$ makes no error on a particular trial, ST = MT (see Fig. 1).

Now, if $S$ is given a number of trials at this task, the IP is defined as the within-S correlation between $\mathrm{AE}$ and ST. That is, over $n$ trials, there are $n$ AE-ST pairs, and the relationship between these two variables is determined for a particular $S$ by correlating the two arrays. This score can be used as a dependent variable if it is transformed to $Z^{\prime}$ prior to analysis.

If $\mathrm{S}$ is preprogramming completely, i.e., if no feedback produced during the movement is used to modify that response while it is in progress, then the neuromotor program for the movement will have been determined in advance. In addition, $S$ will have to choose an appropriate ST in advance so that the end of the programmed movement coincides with the clock's endpoint. If the chosen ST is too late, $\mathrm{AE}$ will be positive (indicating a late response), and if the ST is too early, $\mathrm{AE}$ will be negative. Therefore, if the movement is entirely preprogrammed the IP should tend toward 1.00 . However, if $S$ is responding on the basis of feedback in, for example, a movement which is very long in time (e.g., $0.5 \mathrm{sec}$ ), then the ST will have little to do with the final AE because $S$ will use feedback (probably visual) during the movement to determine the time of the movement's endpoint. Therefore, under such conditions, the IP should tend toward zero. Since conditions which permit maximum utilization of feedback (e.g., movements long in time) should lead to IPs near zero, and the conditions prohibiting the use of feedback (e.g., movements short in time) should produce IPs near 1.00 , the IP has the potential to serve as an index of the degree of feedback involvement in movement.

\section{VALIDATION OF THE IP}

A coincidence-anticipation task involving receptor anticipation (Poulton, 1952) was used. S was seated at a large table, and a small circular (1 cm diam) target, visible for $1.4 \mathrm{sec}$, approached horizontally from the direction he was facing. $S$ grasped a handle attached to a slide which ran in a trackway mounted along S's end of the table at right angles to the direction of target movement. A pointer attached to the slide extended away from $\mathrm{S}$. Beginning with the slide against a stop at S's right, when the target approached, $S$ moved the slide so that the pointer "hit" the target as they crossed paths. All Ss received 20 trials with KR. Procedures and apparatus are described more fully in Schmidt (1969).

The IP was computed as described above. Algebraic error ( $A E$ ) was the signed error indicating whether $S$ was early or late in "hitting" the target. Starting time (ST) was the interval from S's first movement until the target reached the location at which it was to be "hit." Movement time (MT) was the interval from S's first movement until his pointer crossed the target's path. The IP was the within-S correlation between $\mathrm{AE}$ and ST over the last 15 trials.

The data for the present study were originally collected to determine the effect of various response variables on the timing accuracy in "hitting" the target. Movement speed was varied by having $S$ move either at "maximal" or at "moderate" speed. Movement distance was varied by varying the location of a stop defining the origination of the movement so that the movement distance was $15,30,45$, or $60 \mathrm{~cm}$. The load on the movement was varied by adding or not adding an 8.5-1b load which resisted the right-left movement of the slide. The 16 ( 2 by 4 by 2) treatment combinations each had 10 randomly assigned right-handed male undergraduate Ss.

If the IP is a valid measure of the extent to which the "hitting" response is preprogrammed, then these response variables should be strong in determining the IP. For example, slower movement speed (longer MT) $-144 \mathrm{msec}$ for "maximal" and $220 \mathrm{msec}$ for "moderate", speed-would provide $S$ with greater time during which to adjust the movement in response to feedback generated during the movement, leading to decreased IP. Increased movement distance also lengthened MT $(115,165,203$, and $245 \mathrm{msec}$ for the $15-, 30-, 45-$, and $60-\mathrm{cm}$ movements), and should lead to decreased IP. Addition of the load did not change MT appreciably, but should provide inertial resistance to changes in velocity which should reduce S's ability to utilize the feedback to control the movement, leading to an increased IP.

The effects of the movement variables on the IPs were determined after transforming each IP to $Z^{\prime}$ (Table 1). All of the IPs were fairly large $(>.60)$, which probably reflected the fact that the MTs were relatively short $(<.28 \mathrm{sec})$, a condition which should not have allowed extensive use of feedback during the movements. Increasing the movement speed from "moderate" to "maximal" raised the IP from mean $r=.696$ to .886 , which was significant with $F(1,144)=42.87$, $\mathrm{p}<.001$. Increasing the movement distance depressed the IP with mean $r$ $=.874, .794, .821$, and .730 for the progressively increasing distances. These differences were significant with $F(3,144)=4.65, p<.05$. Adding the load increased the IP from mean $r=$ .782 to .834 , which was significant with $F(1,144)=3.99, \quad p<.05$. Therefore, in each case the effects of the movement variables were as predicted from programming theory.

However, some potential criticisms should be examined before the IP can be endorsed as a measure of preprogramming. If there is interest in, say, the effects of practice on preprogramming, one needs to know the extent to which the change in the distributions of ST and/or AE per se as a function of practice will cause changes in the IP. It is well known that correlations are somewhat sensitive to changes in the skewness of distributions, to limitations in the ranges of the variables, etc. For example, if $S$ always chose the same ST, the IP would be zero, owing to the zero variance in ST. However, although Ss do tend to attempt to hold ST constant, they are unable to do so perfectly, and a constant ST would probably never occur in practice. Also, if the experimental variable (e.g., practice) produces changes in the shapes of the AE or ST distributions, the IP might be 
Table 2

Mean IPs for Raw Scores and After Various Transformations for Maximal and Moderate Speed Movements $(N=10)$

\begin{tabular}{|c|c|c|c|c|c|c|c|c|}
\hline & & \multicolumn{7}{|c|}{ Transformation } \\
\hline & & $\begin{array}{c}\text { Raw } \\
\text { Scores }\end{array}$ & $\begin{array}{c}\text { SQRT } \\
\text { ST }\end{array}$ & $\begin{array}{c}\log _{e} \\
\text { ST }\end{array}$ & $\begin{array}{c}\text { RECIP* } \\
\text { ST }^{2}\end{array}$ & $\begin{array}{c}\text { SQRT } \\
\text { AE }\end{array}$ & $\begin{array}{c}\log _{e} \\
\mathrm{AE}\end{array}$ & $\begin{array}{c}\text { RECIP* } \\
\text { AE }\end{array}$ \\
\hline Maximal & $\begin{array}{l}\text { IP } \\
Z^{\prime}\end{array}$ & $\begin{array}{l}.805 \\
1.13\end{array}$ & $\begin{array}{l}.804 \\
1.11\end{array}$ & $\begin{array}{l}.802 \\
1.04\end{array}$ & $\begin{array}{l}-.740 \\
-.95\end{array}$ & $\begin{array}{c}.805 \\
1.13\end{array}$ & $\begin{array}{c}.767 \\
1.01\end{array}$ & $\begin{array}{r}-.804 \\
-1.11\end{array}$ \\
\hline Moderate & $\begin{array}{l}\text { IP } \\
Z^{\prime}\end{array}$ & $\begin{array}{l}.766 \\
1.01\end{array}$ & $\begin{array}{l}.762 \\
1.00\end{array}$ & $\begin{array}{l}.740 \\
0.95\end{array}$ & $\begin{array}{l}-.696 \\
-.86\end{array}$ & $\begin{array}{l}.761 \\
.99\end{array}$ & $\begin{array}{l}.620 \\
.72\end{array}$ & $\begin{array}{l}-.731 \\
-.93\end{array}$ \\
\hline
\end{tabular}

* Reciprocal transformation reverses the sign of the correlation

influenced by the changes in skewness as well, and one could not be sure that IP changes as a function of practice represented changes in programming or changes in the distributions of $\mathrm{AE}$ or ST. Therefore, in order to examine the effects of changes in the $\mathrm{AE}$ and ST distributions on the IP, the IPs from a subsample of $10 \mathrm{Ss}$ ( 5 from the longest movement and 5 from the shortest) were reanalyzed after transforming the $\mathrm{AE}$ and $\mathrm{ST}$ scores separately in ways which are known to change the shapes of the distributions (see Edwards, 1960, pp. 128-131). The IPs were recomputed following (1) a square root transformation, (2) a $\log _{e}$ transformation, and (3) a reciprocal transformation of the AEs and STs hopefully, will lead to the establishment of various laws governing the use of feedback in movement control.

\section{REFERENCES}

ADAMS, J. A. A closed-loop theory of motor learning. Joumal of Motor Behavior, 1971, 3, 111-150.

CHRISTINA, $R$ W Minimum visual feedback processing time for amendment of an incorrect movement. Perceptual \& Motor Skills, 1970, 31, 991-994.

HENRY, F. M. Increased response latency for complicated movement and a 'memory-drum' theory of neuromotor reaction. Research Quarterly, 1960,31, 448-458.

HENRY, F. M., \& HARRISON, J. S Refractoriness of a fast movement Perceptual \& Motor Skills, 1961, 13, $351-354$.

HICK, W. E. Discontinuous functioning of the human operator in pursuit tasks. Quarterly Journal of Experimental Psychology, 1948, 1, 36-57.

KEELE, S. W., \& POSNER, M. I. Processing of feedback in rapid movements. Journal of Experimental Psychology, 1968, 77, 353-363.

POULTON, E. C. The basis of perceptual anticipation in tracking. British Journal of Psychology, 1952, 43, 295-302.

SCHMIDT, R. A Movement time as a determiner of timing accuracy. Journal of Experimental Psychology, 1969,79, 43-47.

SCHMIDT, R. A. Proprioception and the timing of motor responses. Psychological Bulletin, 1971, 76, 383-393. 